\title{
Alfabetização Científica: apropriações discursivas no desenvolvimento da escrita de alunos em aula de Ecologia
}

\section{Scientific Literacy: discursive appropriations on students' writing development in Ecology class}

\author{
Mayumi Yamada ${ }^{1}$ mayumiyamada@usp.br \\ Marcelo Tadeu Motokane ${ }^{2}$ mtmotokane@ffclrp.usp.br
}

\begin{abstract}
RESUMO
Um ponto importante para o processo de alfabetização científica é o desenvolvimento das habilidades de leitura e escrita do aluno uma vez que, as formas textuais da ciência são bastante peculiares e distantes da linguagem do nosso cotidiano. Com o intuito de melhor compreender esse processo, buscamos neste trabalho entender o desenvolvimento da escrita de alunos do $6^{\circ}$ ano em uma aula de Ecologia. Especificamente, olhamos se os alunos se apropriam de discursos alheios, de que maneira isso é feito e a relação disso com a qualidade conceitual das produções escritas. Para isso uma sequência didática sobre mudanças na vegetação de uma restinga foi aplicada, gravada e, posteriormente, transcrita e analisada. Observamos que as apropriações são bastante evidentes e estabelecem uma relação direta com a qualidade conceitual das explicações. Adotando uma perspectiva dialógica da linguagem, fica aparente a importância do outro na construção do conhecimento de um indivíduo. Nesse sentido, é importante que, para o ensino que almeja a alfabetização científica, esse processo seja levado em consideração. Além disso, que o discurso do professor e o discurso do material utilizado em sala de aula sejam conectados evitando que os alunos façam reproduções com erros conceituais e que posteriormente possam se tornar discursos próprios e cientificamente equivocados.
\end{abstract}

Palavras-chave: Ensino de Ciências, Alfabetização Científica, Interação Verbal.

1 Instituto de Física/Universidade de São Paulo

2 - Faculdade de Filosofia, Ciências e Letras de Ribeirão Preto/Universidade de São Paulo 


\section{ABSTRACT}

An important aspect of the scientific literacy is the student's development of reading and writing skills, since the textual forms in science are quite peculiar and far from our everyday language. In order to better understand this process, we sought in this paper to comprehend the development of 6th grade student's writing on an Ecology class. Specifically, we observed whether the students get hold of other people's speeches, in which way this is done and its relation to the conceptual qualities of written productions. For this a didactical sequence about changes on a sandbank vegetation was applied, recorded and, later on, transcribed and analyzed. We observed that appropriations are quite evident and establish a direct relation to the conceptual quality of the explanations. Adopting a dialogical perspective on language, the relevance of the other on the building of one's knowledge becomes clear. Therefore, it is important that, for the teaching which seeks scientific literacy, this process should be taken in consideration. Moreover, that the material used in classroom and the teacher's speeches are connected, avoiding students to reproduce conceptual mistakes and making them their own scientific errors.

Keywords: Science teaching, Science literacy, Verbal interaction. 


\section{INTRODUÇÃO}

Diante da ascensão da cultura científica e tecnológica na sociedade, é importante que a educação científica promova condições para que os alunos participem ativamente dessas questões como um membro crítico e consciente.

Ser alfabetizado cientificamente não significa ser um cientista ou possuir todo conhecimento sobre as ciências, mas que o aluno tenha acesso a um conjunto de ações que caracterizam a cultura científica, por exemplo, formular hipóteses, desenvolver habilidades de leitura e escrita, explicar fenômenos e argumentar. Porém, não são apenas essas ações que caracterizam a cultura científica. A cultura científica possui regras, valores, modos de produção, validação e divulgação que lhe são peculiares (CACHAPUZ et al., 2005), assim como também lhe é peculiar a linguagem compartilhada entre os membros dessa cultura.

Entendemos a linguagem como elemento essencial de interação e comunicação: é intrínseca nas culturas da sociedade, inclusive na cultura científica, constituindo-se como meio de produção do conhecimento e também de construção de uma identidade social. Nesse sentido, assumimos neste trabalho, uma perspectiva dialógica do Círculo de Bakhtin em que os processos comunicativos são muito mais do que palavras transmitidas de um sujeito para outro, a linguagem é papel constitutivo dentro de uma cultura. Ou seja, por meio da linguagem, o homem não só veicula informações, mas também permite aos sujeitos se representarem a si mesmos, aos outros e ao mundo (PANCERA, 2002).

Sendo assim, a linguagem é entendida como ferramenta da interação verbal, o que implica entendê-la como um fenômeno que se realiza por meio da enunciação. $\mathrm{O}$ enunciado dialógico pode ser definido como unidade real da comunicação discursiva: não são apenas as sentenças gramaticais, mas também existe uma ligação direta com o discurso verbal e só pode ser compreendido por meio da análise da situação real na qual ele ocorre (BRAIT; MELO, 2005). Os sujeitos só se comunicam por meio de enunciados quando conhecem e compreendem o contexto, ou seja, quando compartilham universos, conhecimentos, pressupostos e sentidos (BAKHTIN, 2006). Assim, o centro organizador da enunciação não é interior, mas exterior, está situado no meio social, nas relações sociais.

Nesse aspecto, o texto escrito também é uma forma de comunicação verbal. Bakhtin considera que texto e enunciação estão no mesmo plano, pois estão inseridos na produção cultural, abertos à simultaneidade de visões. O texto, ao se caracterizar como produto da atividade humana, torna possível perceber sua vinculação às necessidades, aos interesses e às condições de funcionamento das formações sociais em que são produzidos (BRAGA; MORTIMER, 2003), ou seja, o autor do texto possui intenções concretas ao escrever para o seu leitor que faz parte de um determinado meio social.

Dessa forma o conhecimento se constrói, seja ele científico ou não: nas interações entre sujeitos, na medida em que há o compartilhamento de experiências entre os pares de uma comunidade, sendo assim, socialmente construído e validado (DRIVER et al., 1999).

A produção textual, foco deste trabalho, é uma habilidade essencial no processo de alfabetização científica, uma vez que, assim como na ciência, possibilita a organização e estruturação das ideias consolidando o conhecimento. Porém, as formas textuais da Ciência são bastante peculiares, distantes da linguagem do nosso cotidiano. Para Halliday e Martin (1993), características podem representar dificuldades no entendimento do discurso científico, por exemplo:

- uso de definições encadeadas: termos específicos são usados para definirem um outro termo específico.

- metáforas gramaticais: quando uma classe gramatical é substituída por outra.

- descontinuidade semântica: por exemplo, quando o autor não explicita todas relações envolvidas e parece assumir que o leitor consiga inferi-las. 
Outra característica evidente nos textos científicos é a interação existente entre diversos autores que tratam de um mesmo conhecimento. Os textos trazem referências a outros trabalhos de outros pesquisadores, caracterizando um processo ininterrupto de construção do conhecimento.

Levando isso em consideração, no processo de alfabetização científica é importante que existam condições para que os alunos tenham acesso a essas especificidades. Não tal qual são utilizadas nas ciências, mas que se aproximem dessa linguagem para que, de acordo com Sasseron e Carvalho (2011), tenham condições de compreender termos, conhecimentos e conceitos fundamentais; compreender a natureza das ciências e os fatores éticos e políticos que circundam a sua prática; e, por fim, compreender as relações existentes entre ciência, tecnologia, sociedade e meio-ambiente.

No entanto, a alfabetização científica não é adquirida pelos alunos de maneira passiva. O desenvolvimento do conhecimento em sala de aula depende essencialmente de um processo no qual os significados e as linguagens do professor vão sendo apropriados pelos alunos em uma construção compartilhada (MORTIMER; MACHADO, 1997). No caso da escrita em sala de aula, o texto não é uma consequência de um processo individual, puramente cognitivo ou a elaboração de um conjunto de normas gramaticais. Ao contrário, dada a essência dialógica da linguagem, a interação estabelecida com o outro tem função extremamente relevante na construção de significados.

Vinculado à importância da alfabetização científica, o reconhecimento da relevância das interações discursivas em sala de aula é também crescente nas pesquisas que investigam os processos de construção do conhecimento científico na escola. Trabalhos de Lemke (1998), Driver, Newton e Osborne (2000), Jiménez-Aleixandre, Bugallo Rodrigues e Duschl (2000), Mortimer e Scott (2002), Sasseron e Carvalho (2008), Nascimento e Vieira (2009), por exemplo, tratam da importância da linguagem e das interações discursivas no ensino de ciências preocupado com a formação cidadã dos alunos para ação e atuação crítica na sociedade.

Nesse mesmo enfoque, este trabalho busca investigar se o aluno, ao interagir com o professor e o texto, se apropria do discurso destes. Além disso, investigamos como essas apropriações podem refletir no desenvolvimento do texto escrito do aluno. Dessa forma, buscamos compreender a importância dessas interações na construção do conhecimento tendo em vista o processo de alfabetização científica.

\section{METODOLOGIA}

Para este estudo, uma sequência didática foi desenvolvida para que os alunos elaborassem textos escritos explicativos a partir de um problema, tendo como base a leitura de um texto descritivo em que são tratadas relações entre fatores abióticos e estruturas adaptativas de plantas da Restinga.

De acordo com Masseron (1996), podemos definir uma sequência didática como "uma sequência de atividades progressivas, planificadas, dirigidas por um tema, um objetivo geral ou por uma produção”. Além disso, consideramos importante que uma sequência didática: a) tenha um problema central capaz de realmente aproximar os alunos do conhecimento científico, ganhando a atenção e o interesse destes (e não de um imenso corpo teórico descontextualizado); e b) permita que os estudantes usem a imaginação, criatividade, o discurso (especialmente a argumentação) para responder as questões específicas decorrentes do problema central propiciando o desenvolvimento de destrezas inerentes ao trabalho científico como: elaboração de hipóteses, interpretação crítica dos dados obtidos à luz de teorias (GUISASOLA, 2006).

Nesse sentido, utilizamos um dos principais modelos de atividades sugeridos por Erduran (2006): 1) predição-observação-explicação: uma situação problema deve ser pensada na qual os alunos devem levantar e testar hipóteses, construindo argumentos para validar ou refutar explicações sobre o fenômeno em questão e; 2) teorias competitivas: uma pergunta é feita aos alunos e a eles é fornecido um conjunto de dados a respeito do assunto e dois ou mais modelos explicativos para o fenômeno. Nesse tipo de atividade, os alunos devem escolher 
qual modelo consideram o mais correto, embasando seus argumentos no conjunto de dados fornecidos. No nosso caso, optamos pelo modelo predição-observação-explicação descrito a seguir.

A primeira atividade da sequência didática tem início com um trecho de um artigo publicado no Jornal da Ciência que traz dados referentes à elevação do nível do mar e suas consequências para as cidades litorâneas.

Em seguida, fotos ilustram a localização dessas cidades (planícies litorâneas) e o contraste entre uma planície ocupada pela cidade e outra com a vegetação de Restinga ainda preservada. Assim, os alunos são instigados a refletir sobre o que poderia acontecer com as áreas preservadas em consequência da elevação do nível do mar, já que quase não se discute isso na mídia, ao contrário das amplas discussões realizadas acerca da destruição de cidades litorâneas em decorrência desse aumento do nível do mar.

O próximo passo da sequência didática é o desenvolvimento de habilidades argumentativas trabalhada de forma escrita: o aluno escolhe entre duas hipóteses fornecidas, justifica a escolha e faz uma previsão baseada em seus conhecimentos prévios:

1. A vegetação não é afetada, pois

Se a aproximação do mar não afeta a vegetação, então esperamos que

\section{OU}

2. A vegetação pode ser afetada, pois

Se a aproximação do mar afeta a vegetação, então esperamos que

Após essa atividade, inicia-se a atividade 2 em que o aluno tem em mãos uma sequência de fotos (dados) que corroboram uma das hipóteses propostas anteriormente.

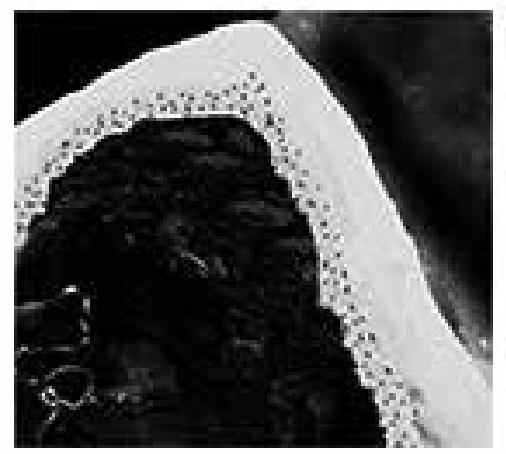

Antes

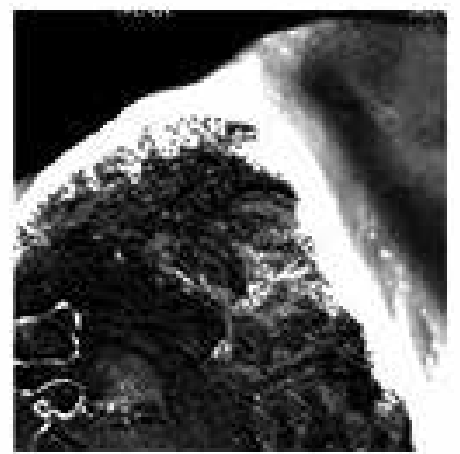

Quinze anos depois

As fotos são explicadas no decorrer do texto da atividade: quinze anos depois da primeira foto, a faixa de areia está mais estreita, evidenciando a elevação do nível do mar e a sua consequente aproximação da vegetação, além disso, mostra que as formações vegetais (herbácea e arbustiva) encontram-se modificadas: onde antes havia uma vegetação predominantemente arbustiva, após quinze anos passa a apresentar herbáceas com mais frequência (pontos vermelhos). Essas formações vegetais são também ilustradas por meio de fotos, focando suas diferenças.

O aluno, então, é desafiado a dar explicações a respeito da situação ocorrida de forma escrita: 
1. Por que, com a aproximação do mar, a vegetação herbácea começou a aparecer com mais freqüência onde antes predominava a vegetação arbustiva?

2. Como se deu esse processo?

Para responder a essas perguntas, o aluno conta com um texto de apoio descritivo. O conteúdo do texto enfatiza as características do ambiente e das plantas de restinga e as estruturas adaptativas das plantas herbáceas dessa região.

Na etapa final, a professora em uma discussão com os alunos retoma as ideias prévias dos alunos da atividade 1, contrastando com as explicações das questões da atividade 2. Podendo, dessa forma, avaliar as respostas dadas ao fim da atividade comparadas à primeira atividade, verificando se ocorreram mudanças de concepções ou então, o quanto as explicações tornaram-se mais completas e com conteúdo científico.

A sequência didática foi aplicada em duas aulas de 50 minutos em uma escola Municipal no interior do Estado de São Paulo e gravadas em áudio e vídeo por um sujeito externo à pesquisa com autorização prévia da instituição escolar e dos pais dos alunos. As gravações das aulas foram transcritas dentro das normas propostas por Petri (1999, p.19-20) e para cada episódio enumeramos os turnos de fala e identificamos os sujeitos das falas, assim como os textos escritos pelos alunos.

Diante das interações do aluno com o professor e com o texto da sequência didática, identificamos nas explicações dos alunos marcas (cópias) do texto e também da fala da professora.

A marca expressa proveniente da voz da professora foi classificada como interação Aluno-Professor; se proveniente do texto da atividade ou do texto de apoio, classificada como interação Aluno-Texto; se a resposta apresentou ambas as marcas, tanto da voz da professora como do texto, classificada como Aluno-Professor-Texto; e, se a resposta do aluno não apresentou nenhuma marca evidente, foi classificada como ausente.

Diante dessas classificações, analisamos o conteúdo das respostas: identificando aquelas que se adequaram ao conhecimento científico, ou seja, sem apresentar erros conceituais; e aquelas que não se adequaram ao conhecimento científico, sejam por terem apresentado erro conceitual ou por não estabelecerem relação entre a pergunta feita com a resposta dada.

Dessa forma investigamos a existência de relações entre as interações e o conteúdo científico dos textos escritos dos alunos para tentar compreender como a apropriação das vozes do professor e do texto reflete na produção escrita do aluno.

\section{RESULTADOS}

Os resultados obtidos na tabela 1 nos mostram que a maior quantidade de ocorrências (46,15\%) é a interação do tipo Aluno-Professor, ou seja, o aluno apresentou marcas da voz da professora na elaboração de sua resposta. Em segundo lugar temos 26,93\% de ocorrências cujas respostas não apresentaram marcas evidentes de vozes da professora, nem do texto. Em terceiro lugar, 23,08\% de ocorrências de alunos que trouxeram cópias do texto em suas respostas e, por fim, apenas 3,84\% que corresponde a uma única ocorrência em que aluno apresentou tanto marcas da voz da professora como do texto.

Tabela 1: Resultados obtidos a partir da análise das marcas da interação em respostas dos alunos. 


\begin{tabular}{|l|l|l|l|}
\hline Interação & Sujeitos & Quantidade de ocorrências & $\begin{array}{l}\text { Porcentagem } \\
\text { correspondente } \\
\mathbf{( \% )}\end{array}$ \\
\hline Aluno-Professor (A-P) & $\begin{array}{l}1,2,4,9,11,13,14,16, \\
18,19,20,21\end{array}$ & 12 & 46,15 \\
\hline Aluno-Texto (A-T) & $7,15,24,10,17,22$ & 6 & 23,08 \\
\hline $\begin{array}{l}\text { Aluno-Professor-Texto } \\
\text { (A-P-T) }\end{array}$ & 3 & 1 & 3,84 \\
\hline Ausente & $5,6,8,12,23,25,26$ & 7 & 26,93 \\
\hline
\end{tabular}

Podemos observar a partir da tabela 2 que houve uma grande diferença no conteúdo conceitual das respostas escritas pelos alunos: 76,92\% não apresentaram conteúdo científico e apenas $23,08 \%$ dos alunos apresentaram conteúdo científico em suas respostas.

Analisando o conteúdo científico de acordo com as interações estabelecidas, pudemos observar que todos aqueles que apresentaram vozes do professor (A-P) nas respostas (46,15\%) não apresentaram conhecimento científico; daqueles que apresentaram marcas do texto da atividade (23,08\%) metade apresentou conhecimento científico (11,54\%) e a outra metade não (11,54\%); A única ocorrência de interação do tipo A-P-T apresentou conhecimento científico, representando 3, 84\%; e por fim, daqueles classificados como ausente (sem marcas evidentes), 19,23\% não apresentou conhecimento científico e 7,7\% apresentou conhecimento científico em suas respostas.

Tabela 2: Resultados obtidos a partir da análise do conteúdo conceitual.

\begin{tabular}{|l|l|l|l|l|}
\hline Interação & $\begin{array}{l}\text { Conhecimento } \\
\text { científico } \\
\text { (sujeitos) }\end{array}$ & $\begin{array}{l}\text { Sem conhecimento } \\
\text { científico (sujeitos) }\end{array}$ & $\begin{array}{l}\text { Porcentagem } \\
\text { correspondente } \\
\text { Conhecimento } \\
\text { científico (\%) }\end{array}$ & $\begin{array}{l}\text { Porcentagem } \\
\text { correspondente } \\
\text { Sem conhecimento } \\
\text { científico (\%) }\end{array}$ \\
\hline $\begin{array}{l}\text { Aluno-Professor } \\
\text { (A-P) }\end{array}$ & ---- & $\begin{array}{l}1,2,4,9,11,13,14,16, \\
18,19,20,21\end{array}$ & 0 & 46,15 \\
\hline $\begin{array}{l}\text { Aluno-Texto } \\
\text { (A-T) }\end{array}$ & $10,17,22$ & $7,15,24$ & 11,54 & 11,54 \\
\hline $\begin{array}{l}\text { Aluno-Professor- } \\
\text { Texto (A-P-T) }\end{array}$ & 3 & ---- & 3,84 & 0 \\
\hline Ausente & 5,6 & $8,12,23,25,26$ & 7,7 & 19,23 \\
\hline
\end{tabular}

\section{DISCUSSÃO}

\section{ALUNO-PROFESSOR (A-P)}

Os resultados nos mostram que a maioria dos alunos expressou em suas respostas interação do tipo Aluno -Professor, trazendo marcas da voz da professora em seus textos escritos. Porém, se atentarmos para a qualidade das respostas nenhuma das explicações foi adequada quanto ao conhecimento científico, ou seja, as explicações apresentaram erros conceituais marcados no discurso da professora e que de alguma forma influenciaram no desenvolvimento das explicações dos alunos.

Por exemplo, o uso termo "invadiu” (Ex.1), pela professora foi marcado em vários turnos: no Episódio 2, os turnos 60, 62, 65, 101 (duas vezes), 105 (duas vezes), 107 (duas vezes), 113 (quatro vezes), 125, 135, 171; no episódio 3, os turnos 07, 11 (duas vezes), 17, 22, 26, 30 (duas vezes) e 34. Esse termo ocorreu em 67\% das 
respostas dos alunos (entre aquelas que apresentaram interação A-P) dando a ideia de que a vegetação herbácea invadiu o território da vegetação arbustiva, destruindo-a (Ex.2).

Exemplo 1. Episódio 2: Turnos de fala 60, 62 e 113 em que professora usa o termo "invadiu”.

Turno 60. perfeito... muito bem... cê tá vendo que essa pontilhada ele tá invadindo a vegetação...

Turno 62. ...então a gente viu que com a diminuição da espessura de areia a vegetação herbácea depois arbustiva a gente vê uma vegetação herbácea invadindo a...

Turno 113 ... aqui existia uma vegetação herbácea... não tinha?que agora depois do avanço do mar a gente viu que ela começou a invadir o lugar da outra vegetação... a arbustiva... não é?a gente quer saber o por que ela conseguiu invadir... se ela conseguiu invadir... como ela conseguiu?por que que ela conseguiu invadir? que que ela fez?que que aconteceu com a vegetação arbustiva...

Exemplo 2. Explicações dos alunos com o uso do termo invadir

Com as raízes fortes as plantas herbáceas começam a invadir, porque as plantas arbustiva não são fortes e as plantas herbácea invadem muito facio (A1)

Porque com o avamço do mar elas não tem área, para ficar e com isso elas acabam invadindo a área onde predominava a vegetação arbustiva (A11).

A vegetação herbácea e muito pequena e a arbustiva e muito grande então o herbacia conseguil invadir (A20).

\section{ALUNO-TEXTO (A-T)}

As marcas encontradas (Ex. 3) nas interações Aluno-Texto nas respostas que apresentaram conhecimento científico foram todas extraídas de um mesmo trecho do texto de apoio (Ex. 4).

Exemplo 3. Resposta de A17

Porque com a força da água que atinge a praia é possível que uma abertura se forme que possibilita a adentração da vegetação herbácea no território da arbustiva e isso só ocorre graças as características da vegetação arbustiva que faz com que ela não consiga viver nas proximidades da água diferente da herbácea que tem raízes profundas, rizoma e coroa que possibilita a sobrevivência dela nesses locais..

Exemplo 4. Trecho do texto do material de apoio

A vegetação herbácea possui raízes bastante profundas e sistemas de raízes e rizomas que fixam as plantas na areia e as mantém mais estáveis, já que a areia da praia se movimenta com muita facilidade devido ao vento.

Isso pode ter acontecido pelo fato da professora ter reforçado essas características no decorrer da leitura do texto de apoio. Ao falar sobre as características da vegetação arbustiva, ela faz uma comparação com a vegetação herbácea retomando justamente as características das raízes e rizoma (Ex.5).

Exemplo 5. Episódio 2. Turno 95. Fala da professora retomando característica da vegetação herbácea.

Turno 95. ... é mais densa (vegetação arbustiva)... ou seja... mais fechada... certo? vamo dá uma estudada nela... essas plantas recebem menor influência do mar... ou seja do sal... da salinidade e dos ventos... o terreno ele é mais estável... lembra que lá era areia? e que as plantas tinha que ter raízes fortes e rizomas pra elas 
poderem ficar fixas lá... aqui não... aqui o solo ele já é mais estável e as condições de fixação das raízes das plantas melhoram... né elas conseguem ficar mais fixas...

Já aquelas que não se adequaram ao conhecimento científico trazem marcas do texto como cópias, porém as cópias não apresentam relação com a pergunta e a resposta dada (Ex.6), aparentemente, os alunos extraíram trechos do texto de apoio aleatoriamente utilizando-as como resposta.

Exemplo 6. Cópia de trecho do texto como resposta à pergunta

Após a vegetação herbácea, as plantas começam a ficar mais altas e andar, entre elas começa a ficar difícil pois a vegetação é muito mais densa: é a vegetação arbustiva, que pode chegar a 3 metros de altura. (A24)

\section{ALUNO-PROFESSOR-TEXTO (A-P-T)}

A interação estabelecida entre aluno, professor e texto foi um caso particular em que o aluno apresentou dificuldades no entendimento da questão e que a princípio achou que bastava copiar alguma parte do texto como resposta (Quadro 1). Diante disso, a professora acompanhou o desenvolvimento de A3 tirando suas dúvidas e guiando seu raciocínio. Essa postura da professora refletiu na explicação do aluno, trazendo marcas da sua voz e também do texto dando suporte a sua resposta (Ex. 7).

Quadro1: Episódio 3. Turnos de fala da professora e A3.

\begin{tabular}{|l|l|l|}
\hline Turno & Sujeito & Fala \\
\hline 31 & Professora & $\begin{array}{l}\text { ó...a gente sabe que a aproximação do mar fez com que a vegetação herbácea } \\
\text { invadisse o lugar da arbustiva...é ou não é?como que ela conseguiu invadir? }\end{array}$ \\
\hline 32 & A3 & onde tá escrito? \\
\hline Professora & $\begin{array}{l}\text { não não tá escrito...você tem que formular...ce tem que resolver o problema...né...e } \\
\text { aqui você tem o material de apoio...pra apoiar você a responder...gente ((se volta } \\
\text { para a sala toda)) vocês não vão achar uma resposta pronta no texto...né...vocês } \\
\text { vão ter que contruir...né...resolver o problema...vocês vão construir sua resposta } \\
\text { com a ajuda do texto certo? }\end{array}$ \\
\hline 33 & A3 & ( ) \\
\hline 34 & Professora & $\begin{array}{l}\text { ó...a gente sabe que a vegetação herbácea... ó...com a espessura bem próxima do } \\
\text { mar ela ficava aqui não ficava?quando essa espessura diminuiu o mar se aproximou } \\
\text { e ela conseguiu invadir e tomar o lugar da vegetação arbustiva...que característica } \\
\text { tem uma planta herbácea?que cara... }\end{array}$ \\
\hline 35 & A3 & ela tem as raízes... \\
\hline 36 & Professora & isso...tem as raízes o que? \\
\hline 37 & A3 & Fortes \\
\hline 38 & Professora & $\begin{array}{l}\text { que pode fixar...não é? que características tem as plantas arbustivas uma planta } \\
\text { arbustiva com as características que ela tem ela consegue sobreviver num lugar } \\
\text { mais próximo do mar? e a planta herbácea...ela é mais apropriada...ela consegue? } \\
\text { tenta resolver o problema nesse sentido }\end{array}$ \\
\hline
\end{tabular}

Exemplo 7. Resposta de A3

Porque o nível da água do mar subiu e deu mais sobrevivência para a vegetação herbácea 
Porque a herbácea foi mais apropriada para viver em lugar próximo ao mar por ter as raízes bastante profundas e o sistema das raízes é um rizoma e que fixa as plantas na areia e mantém as herbáceas mais estáveis.

\section{AUSENTE - SEM MARCAS DE INTERAÇÃO}

Por fim, grande parte dos alunos não apresentou marcas evidentes da interação em suas repostas. A princípio isso poderia ser interpretado como uma atitude de maior autonomia no desenvolvimento das respostas, ou seja, sem que esses alunos precisassem de qualquer suporte (a voz da professora ou o texto da atividade) para sustentar seu ponto de vista. Porém, a análise do conteúdo conceitual das respostas nos mostra que a maioria não se adequou ao conhecimento científico, por exemplo, nas respostas de A8 e A23 (Ex.8). Nesses casos, os alunos partem de uma visão catastrófica, não gradual do avanço do mar.

Exemplo 8. Respostas de A8 e A23

Porque o mar tomou tudo e destruiu a vegetação arbustiva. Porque a planta herbácea com o mar ela foi expalhando pela vegetação arbustiva e a planta arbustiva está morrendo por conta da água (A8).

Esse processo se deu a vegetação que começou a se expandir através dos ventos e do mar com isso ela foi se expalhando pela vegetação (A23).

Diferente disso, tivemos apenas duas ocorrências de alunos que não apresentaram marcas evidentes da interação nas respostas, mas estavam de acordo com o conhecimento científico como é o caso de A5 (Ex.9).

Exemplo 9. Resposta de A5

Pois seu espaço esta sendo coberto pelo avanço do mar.

Pois a planta arbustiva não tem características para viver perto do mar, então ela acaba morrendo e a planta herbácea toma seu espaço (A5).

\section{CONCLUSÕES}

A análise dos resultados nos mostra que existem marcas linguísticas aparentes das interações verbais estabelecidas na aula e são expressas nos textos escritos pelos alunos. As relações entre as interações e a qualidade das explicações dos alunos nos mostram a importância do outro na constituição de um enunciado. E consequentemente na construção do conhecimento.

A professora, ao interagir com o texto, apresenta ao aluno uma visão a partir da sua leitura, ou seja, produz o seu sentido da leitura realizada. Da mesma forma, o aluno produz outro sentido ao texto ao interagir com a professora, ocorrendo o mesmo na sua interação direta com o texto escrito.

A elaboração da reposta escrita pelo aluno em sala de aula envolve todo o quadro enunciativo, não se limitando apenas ao momento da pergunta - resposta individual. Isso pode ser visto na grande influência da voz da professora nas respostas dos alunos ao fazer a leitura e a explicação do texto da atividade e também no próprio texto da sequência didática, que carrega um valor social que o aluno utiliza como apoio às suas respostas nas interações aluno-texto.

A interação aluno-professor-texto representa a importância do professor como mediador, uma vez que A3, ao apresentar dúvida no entendimento do problema requisitou a presença da professora, que a guiou no en- 
tendimento da questão, não fornecendo a resposta de imediato, mas desenvolvendo um processo argumentativo levantando elementos para que a aluna desenvolvesse sua explicação. Dessa forma, sua resposta incorporou elementos desse diálogo e também de partes do material de apoio.

Da mesma forma em que a mediação da professora foi essencial na construção da resposta de A3, a interação aluno-professor também conduziu a erros conceituais. Sabendo que reproduções fazem parte do processo de aprendizado das ciências, é importante que alguns termos que são muitas vezes utilizados como metáforas de características humanas, por exemplo, "raízes fortes/fracas" ou a vegetação "invadiu” sejam empregadas com bastante cautela para que o aluno não tenha uma compreensão equivocada.

Sabemos que existem diversos elementos que fazem parte do quadro enunciativo, tanto em respostas que apresentaram marcas de interação quanto nas que não apresentaram, por isso, esse estudo em particular, obviamente não esgotará tantos possíveis olhares dentro da uma sala de aula. Mas, por meio desta pesquisa foi possível observar a importância do papel do professor e do material utilizado em sala de aula. O aluno em seu processo de construção de conhecimento apresenta fases em que se apropria de discursos alheios. Sendo assim, no processo de alfabetização científica, é importante que o discurso do professor e o material utilizado em sala de aula estejam conectados, uma vez que os alunos reproduzem tanto o que é considerado cientificamente aceito, mas também termos e ideias equivocadas. Uma vez internalizados os discursos equivocados, mais difícil será a desconstrução desse conhecimento formado.

\section{REFERÊNCIAS}

BAKHTIN, M. (Volochinov). Marxismo e filosofia da linguagem. 12. ed. São Paulo: Hucitec. 2006.

BRAGA, S. M. A.; MORTIMER, E. F. Os gêneros de discurso do texto de Biologia dos livros didáticos de ciências. Revista Brasileira de Pesquisa em Educação em Ciências, v.3, n.3, 2003.

BRAIT, B.; MELO, R. Enunciado/enunciado concreto/enunciação. In: BRAIT, B. (org.) Bakhtin: conceitoschave. São Paulo: Contexto. 2005.

CACHAPUZ, A.; GIL-PEREZ, D.; CARVALHO, A. M. P.; PRAIA, J.; VILCHES, A. (orgs.). A necessária renovação do ensino das ciências. São Paulo: Cortez, 2005.

DRIVER, R.; ASOKO, H.; LEACH, J.; MORTIMER, E.; SCOTT, P. Construindo conhecimento científico na sala de aula. Química Nova na Escola, v.9, p.31-40, 1999.

DRIVER, R.; NEWTON, P.; OSBORNE, J. Establishing the norms of scientific argumentation in classrooms. Science Education, Hoboken, v. 84, n. 3, p. 287-312, 2000.

ERDURAN, S. Promoting ideas, evidence and argument in initial science teacher training. School Science Review, v.87, p.45-50, 2006.

GUISASOLA, J.; FURIÓ, C.; CEBERIO, M. Science education based on developing guided research. In: Thomase M.V. (Ed.). Science Education in Focus. 2006.

HALLIDAY, M.; MARTIN, J. R. Writing science: literacy and discursive power. Pittsburgh, Pa: University of Pittsburgh Press. 1993.

JIMÉNEZ-ALEIXANDRE, M. P.; BUGALLO RODRÍGUEZ, A.; DUSCHL, R. A. "Doing the lesson” or "doing science”: argument in high school genetics. Science Education, Hoboken, v. 84, n. 6, p. 757-792, 2000.

KLEIMAN, A. Oficina de leitura: teoria e prática. Campinas. Pontes: ed. Unicamp, 1993.

LEMKE, J. Multiplying meaning: visual and verbal semiotics in scientific text. In: MARTIN, J.; VEEL, R. (Ed.). Reading science: critical and functional perspectives on the discourses of science. London: Routledge, p. 87-113, 1998. 
MASSERON, C. Présentation. Pratiques, v. 92, p. 3-4. 1996.

MORTIMER, E. F.; MACHADO, A. H. Reflexões para o Ensino de Ciências. Anais do Encontro sobre Teoria e Pesquisa em Ensino de Ciências: linguagem, cultura e cognição, p. 139-162, 1997.

MORTIMER, E. F.; SCOTT, P. Atividade discursiva nas salas de aula de ciências: uma ferramenta sociocultural para analisar e planejar o ensino. Investigações em Ensino de Ciências, Porto Alegre, v. 7, n. 3, p. $283-306,2002$.

NASCIMENTO, S. S.; VIEIRA, R. D. Uma visão integrada dos procedimentos discursivos didáticos de um formador em situações argumentativas de sala de aula. Ciência \& Educação, Bauru, v. 15, n. 3, p. 1-15, 2009.

PANCERA, N. K. Linguagem, enunciação, enunciado-ponto de partida para o ensino de língua portuguesa. Educere, v.2, n.1, 2002.

PETRI, D. O discurso oral culto. São Paulo. Humanitas Publicações, 1999.

SASSERON, L. H.; CARVALHO, A. M. P. Almejando a alfabetização científica no Ensino Fundamental: a proposição e a procura de indicadores do processo. Investigações em Ensino de Ciências, Porto alegre, v. 13, n. 3, p. 333-352, 2008.

SASSERON, L. H.; CARVALHO, A. M. P. Alfabetização científica: uma revisão bibliográfica. Investigações em Ensino de Ciências, Porto Alegre, v. 16, n.1, p. 59-77, 2011. 